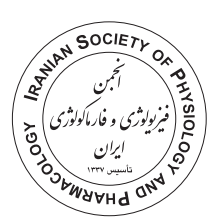

\title{
Oxidative stress profile following the co-administration of cisplatin and resveratrol in female rats: a preliminary study
}

Izuchukwu Azuka Okafor ${ }^{1,2,3}$ (D)

1. Department of Anatomy, Faculty of Basic Medical Sciences, College of Health Sciences, Nnamdi Azikiwe University, Nnewi Campus, PMB 5001, Nnewi, Nigeria

2. Department of Obstetrics and Gynecology, Faculty of Clinical Sciences, College of Medicine, University of Ibadan, Ibadan, Nigeria

3. Pan African University of Life and Earth Science Institute (Including Health and Agriculture) PAULESI, University of Ibadan, Ibadan, Nigeria

\begin{abstract}
Introduction: Cisplatin is one of the most widely used drugs for the treatment of various cancers but has oxidative tissue damage as one of its side effects. This study investigated the oxidative stress profile in some important body tissues following the co-administration of cisplatin (CIS) and resveratrol (RSV).

Methods: Thirty-five adult female rats with an average body weight of $162 \mathrm{~g}$ were divided into 5 groups $(\mathrm{n}=7)$ and used for this experimental study. Group A served as the normal control group and received distilled water only. Group B received only a single dose intraperitoneal injection of $10 \mathrm{mg} / \mathrm{kg}$ CIS. Groups C, D and E were orally given 5, 10 and $20 \mathrm{mg} / \mathrm{kg}$ of RSV respectively for 7 days, starting $24 \mathrm{~h}$ after a single CIS dose intraperitoneal injection of $10 \mathrm{mg} / \mathrm{kg}$. Selected body tissues were harvested for oxidative stress profiling at the end of the experiment.

Results: CIS significantly increased malondialdehyde levels and decreased glutathione, superoxide dismutase and catalase levels in all the tissues assessed (ovary, uterus, liver, kidney, pancreas, stomach and spleen) when compared to the normal control. The RSV treatment caused the reversal of these effects; malondialdehyde levels were significantly decreased, while glutathione, superoxide dismutase and catalase levels were significantly increased across all the examined tissues.

Conclusion: RSV at different doses could be effective in the management of CIS-induced oxidative stress and lipid peroxidation across some body tissues. However, this effect may be dependent on the dose of CIS and RSV.
\end{abstract}

Keywords: Cisplatin Oxidative stress Resveratrol Antioxidants

\section{Introduction}

Cisplatin (CIS) is a platinum-based chemotherapeutic drug used in the treatment of different forms of solid tumors such as ovarian, testicular, lungs, and brain cancers (Yao et al., 2007). However, despite the efficacy of CIS as an anti-cancer agent, its use is primarily restricted due to numerous toxic side effects like nephrotoxicity, hepatotoxicity, ototoxicity and testicular toxicity (Watanabe et al., 2000; Nematbakhsh et al., 2012; Okafor et al., 2014; Mir et al., 2015). CIS is often

\footnotetext{
* Corresponding author: Izuchukwu Azuka Okafor, iza.okafor@unizik.edu.ng
} Received 22 July 2020; Revised from 7 October 2020; Accepted 27 October 2020

Citation: Okafor IA. Oxidative stress profile following the co-administration of cisplatin and resveratrol in female rats: a preliminary study. Physiology and Pharmacology 2021; 25: 134-145. http://dx.doi.org/10.32598/ppj.25.2.90 
thought to trigger cellular apoptosis by inhibiting DNA synthesis and causing crosslink with DNA (Okafor et al., 2014). The clinical use of CIS has been reported to exert severe side effects on different organs of the body. In humans, CIS has been reported to trigger cardiotoxicity through lipid peroxidation, which induces oxidative stress, causing physical injury and damages to myocytes (Hanchate et al., 2017). Although the exact individual mechanism through which CIS exerts its damaging effects on different organs of the body is not entirely the same, the induction of oxidative stress damage, the alteration of tissue antioxidant defense system and the generation of reactive oxygen species (ROS) have been strongly linked to the pathogenesis of CIS-induced toxicity (Coskun et al., 2013). ROS are composed of highly reactive molecules such as hydrogen peroxide $\left(\mathrm{H}_{2} \mathrm{O}_{2}\right)$, hydroxyl radical and superoxide radical, which can chemically interact with cellular components such as proteins, lipids, sugar or nucleotide (Bhattacharjee, 2005; Marrocco et al., 2017). The interactions of these free radicals with cellular components destabilize the biomolecules of the cell, triggering a large chain of free radical reactions that ultimately destroys cellular structural integrity, causing tissue and organ damage (Amin et al., 2008; Nandi et al., 2019). In addition to ROS production and oxidative stress induction, other suggested underlying mechanism involved in CISinduced toxicity includes alteration in $\mathrm{Ca}_{2}{ }^{+}$homeostasis, apoptosis, and the activities of pro-inflammatory genes such as COX-2 (Mir et al., 2015).

Resveratrol (RSV) is a polyphenol phytoalexin found in edibles like grapevine, peanuts and red wine (Shrikanta et al., 2015). It is classified as a phytoestrogen due to its estrogenic properties and has been shown to possess numerous health benefits (Szkudelska and Szkudelski, 2010). Studies involving RSV have reported its anti-cancer, antidiabetic, antiinflammatory and neuroprotective properties (Frémont, 2000; Athar et al., 2009; Fukui et al., 2010; Hamadi et al., 2012). RSV also possesses antioxidant and cardioprotective properties, as it has been reported to inhibit lipid peroxidation, elevate serum levels of low-density lipoprotein cholesterol and inhibit the generation of ROS in the liver and brain (Tadolini et al., 2000; Gedik et al., 2008; Fukui et al., 2010; Akbel et al., 2018). The inhibition and removal of oxidative stress are primary preventive and interventive action against oxidative- induced tissue damage. Several defense systems have been put in place within cells to prevent and remove uncontrolled increase and production of ROS (Marrocco et al., 2017). Enzymatic antioxidants such as catalase (CAT) and superoxide dismutase (SOD), as well as nonenzymatic antioxidants like glutathione (GSH), vitamin $\mathrm{A}, \mathrm{C}$ and $\mathrm{E}$, are known endogenous antioxidants that inhibit the production of such reactive species, protect the cell against tissue damage and maintain balance (Marrocco et al., 2017). There is a need to demonstrate RSV activities against CIS-induced oxidative damage in several tissues to give a clearer view of its antioxidative potential. This study assessed the oxidative stress profile of some important body tissues, following the coadministration of CIS and RSV in adult rats.

\section{Materials and methods}

\section{Study setting}

This experimental study was carried out in the research laboratory of the Department of Anatomy, College of Medicine of the University of Lagos, Nigeria as a preliminary part of a thesis.

\section{Ethical considerations}

Ethical approval was obtained from the College of Medicine of the University of Lagos Health Research Ethics Committee (CMULHREC) with ID number CMULHREC/09/16/025. The experimental procedures of this study complied with the National Research Council (US) and National Health Research Ethics Committee of Nigeria (NHREC) guidelines for the care and use of laboratory animals (NRCC 2011, NHREC 2014).

\section{Animal Care and Handling}

Thirty-five adult female Sprague-Dawley rats were procured from the Animal House, College of Medicine of the University of Lagos. They were acclimatized for two weeks to exclude any intercurrent infection under standard housing of $24 \pm 2^{\circ} \mathrm{C}$ and $12 \mathrm{~h}$ light/dark cycle. The rats were fed with standard rat chow and water $a d-$ libitum throughout the experimental period. The rats were monitored throughout the study period for any undue drug reaction.

\section{Experimental drugs}

RSV with the brand name 'Restorlyf', manufactured by Nature's Way U.S.A., was procured from Alliance in 
Motion Global Ltd., Ikeja, Lagos, Nigeria. The 325mg of RSV was diluted immediately before each use in $20 \mathrm{ml}$ of distilled water and doses of 5,10 and $20 \mathrm{mg} /$ $\mathrm{kg}$ body weight were administered orally using the oral cannula. The remaining formulation was discarded after each use. The drug dosages and formulations were chosen based on previously published studies on RSV (Bolis et al., 1997; Loehrer et al., 1998). The CIS (Zuplatin, 50mg/50ml) injection manufactured by Taj Pharmaceuticals Ltd. India was procured from Bayston Pharmacy, Mushin, Lagos, Nigeria. The injection was given intraperitoneally according to body weight in a single dose of $10 \mathrm{mg} / \mathrm{kg}$. The drug dosages were chosen based on previously published studies on CIS (Coppin et al., 1996; Rose et al., 1999).

\section{Experimental design}

Thirty-five adult female rats with an average weight of $162 \mathrm{~g}$ were divided into 5 groups $(\mathrm{n}=7)$ and used for this experimental study. Group A served as the normal control group and received distilled water only. Group $\mathrm{B}$ was given only a single dose intraperitoneal CIS injection at $10 \mathrm{mg} / \mathrm{kg}$, and allowed to stay for 7 days before sacrifice. Groups C, D and E were given 5, 10 and $20 \mathrm{mg} / \mathrm{kg}$ RSV respectively for 7 days, starting $24 \mathrm{~h}$ after a CIS single dose intraperitoneal injection of $10 \mathrm{mg} / \mathrm{kg}$. The least significant effect of RSV is being understudied, hence female rats were considered to be preferable for this research as studies have shown cisplatin-induced toxicity to be more pronounced in male rats. The female sex hormones estrogen and progesterone have been shown to inhibit the sodium-potassium ATPase enzyme which may exacerbate cisplatin-induced toxicities like hyponatremia and urinary sodium excretion; the male sex hormone, testosterone, stimulates the enzyme (Stakisaitis et al., 2010).

\section{Animal sacrifice and sample collection}

The animals fasted overnight on the last day of drug administration and were sacrificed the next morning by cervical dislocation for the collection of tissues. Tissues collected include ovary, uterus, stomach, liver, kidney, spleen and pancreas. The tissue samples were homogenized immediately for oxidative stress profiling or were stored at $-40^{\circ} \mathrm{C}$ until further analysis in the case where the immediate analysis was not possible.

\section{Oxidative stress determination}

The tissues were homogenized in a Teflon-glass homogenizer with a buffer containing $1.5 \%$ potassium chloride to get the 1:10 (w/v) whole homogenate. Malondialdehyde (MDA) was measured using the thiobarbituric acid test to determine the concentration of ovarian and uterine MDA levels. CAT and reduced GSH level activity were determined as described by Rukkumani and his colleagues (2004). CAT was assayed colorimetrically at $620 \mathrm{~nm}$ and expressed as $\mu$ moles of $\mathrm{H}_{2} \mathrm{O}_{2}$ consumed per min/mg protein. Reduced GSH was evaluated with Ellman's reagent using $0.2 \mathrm{ml}$ of the tissue homogenate (homogenized in $0.4 \mathrm{M}$, phosphate buffer $\mathrm{pH}$ 7.0) while SOD activity was measured by the method described by Sun and colleagues (1998) using the nitroblue tetrazolium reduction inhibition with xanthine-xanthine oxidase as a superoxide generator.

\section{Statistical analysis}

The results were analyzed using the IBM Statistical Package for the Social Sciences version 21 (IBM SPSS, Chicago, IL, USA). Data were reported as mean \pm SEM and differences between mean and the main effects of treatment group were determined using the one-way analysis of variance (ANOVA) and LSD posthoc tests. The mean difference is significant at the 0.05 level $(P<0.05)$.

\section{Results}

\section{Mortality}

The mortality results are presented in Table 1 . The control group had no deaths. The $57 \%$ of animals in groups 2, 4 and 5 died before the end of the experiment, while $43 \%$ of experimental animals in group 3 died before the end of the study. The total combine mortality observed in all groups was $43 \%$ while the mortality in all groups that received CIS was 54\%.

\section{The animal body weights}

Table 2 shows that the animals across all groups had decreased body weight when the body weight before and after drug administration were compared $(P<0.05)$ except for the control group whose body weight did not change significantly.

Oxidative stress profile following the co-administration of CIS and RSV 
TABLE 1: Mortality rate following the co-administration of CIS and RSV in Sprague-Dawley rats.

\begin{tabular}{|c|c|c|c|c|}
\hline Groups & $\begin{array}{l}\text { Number of deaths re- } \\
\text { corded }\left(\mathrm{X}_{1}\right)\end{array}$ & Mortality (\%) & Death ratio $\left(\mathrm{X}_{1} / \mathrm{N}\right)$ & Survival ratio $\left(\mathrm{X}_{2} / \mathrm{N}\right)$ \\
\hline A (Control) & 0 & 0 & 0.00 & 1 \\
\hline B (CIS Only) & 4 & 57 & 0.57 & 0.43 \\
\hline C (CIS+ Rsv Low) & 3 & 43 & 0.43 & 0.57 \\
\hline D (CIS+ Rsv Med) & 4 & 57 & 0.57 & 0.43 \\
\hline E (CIS+ Rsv High) & 4 & 57 & 0.57 & 0.43 \\
\hline
\end{tabular}

TABLE 2: The mean body weight following the co-administration of CIS and RSV in Sprague-Dawley rats.

\begin{tabular}{|c|c|c|c|c|}
\hline Groups & & Mean \pm SEM (g) & $\mathrm{t}$-value & P-value \\
\hline \multirow[t]{2}{*}{ A (Control) } & Before administration & $140.0 \pm 2.9$ & \multirow[t]{3}{*}{-0.36} & \multirow[t]{3}{*}{0.754} \\
\hline & After administration & $140.7 \pm 4.5$ & & \\
\hline \multirow[t]{2}{*}{ B (CIS Only) } & Before administration & $200.7 \pm 3.0$ & & \\
\hline & After administration & $176.7 \pm 3.0$ & \multirow{2}{*}{4.44} & $0.047^{*}$ \\
\hline \multirow[t]{2}{*}{ C (CIS+ RSV Low) } & Before administration & $170.7 \pm 3.5$ & & \multirow[t]{2}{*}{$0.002^{*}$} \\
\hline & After administration & $144.7 \pm 3.0$ & 22.52 & \\
\hline \multirow[t]{2}{*}{ D (CIS+ RSV Med $)$} & Before administration & $150.7 \pm 3.5$ & \multirow[t]{2}{*}{28.75} & \multirow[t]{2}{*}{$0.001^{*}$} \\
\hline & After administration & $112.3 \pm 2.3$ & & \\
\hline \multirow[t]{2}{*}{ E (CIS+ RSV High) } & Before administration & $149.3 \pm 2.3$ & \multirow[t]{2}{*}{7.21} & \multirow[t]{2}{*}{$0.019^{*}$} \\
\hline & After administration & $115.7 \pm 2.3$ & & \\
\hline
\end{tabular}

\section{Ovary oxidant status}

The mean GSH level was significantly $(P<0.05)$ decreased in all treated groups when compared to the control. The SOD level was significantly $(P<0.05)$ decreased only in group 2. Notably, no significant difference was observed in the mean SOD values of groups 3, 4 and 5 when compared to the control. The CAT level was significantly $(P<0.05)$ decreased in groups $\mathrm{B}$ and $\mathrm{D}$ when compared to the control group. There was a significant increase $(P<0.05)$ in MDA in all treated groups except in group $\mathrm{E}$ when compared to the control. However, when compared to group B, SOD and CAT levels in groups $\mathrm{C}, \mathrm{D}$ and $\mathrm{E}$ showed a significant $(P<0.05)$ increase, while GSH levels in groups $\mathrm{C}$ and E showed a significant $(P<0.05)$ increase. MDA levels were significantly decreased in groups $\mathrm{C}, \mathrm{D}$ and $\mathrm{E}$ when compared to group B. (Table 3).

\section{Uterus oxidant status}

When compared to the control group, CIS administration caused a significant change $(P<0.05)$ in the SOD, CAT and MDA levels but caused no significant difference in the GSH levels. CIS-induced changes were not reversed significantly by RSV across all groups and oxidative parameters except for MDA levels where RSV administration caused a significant reduction $(P<0.05)$. Also, High dose RSV caused a significant increase in CAT levels in group E when compared to the CIS control group $(P<0.05$, Table 4$)$.

\section{Liver oxidant status}

Table 5 shows the oxidative changes caused by CIS and RSV co-administration in the rat liver. GSH, SOD, CAT and MDA were significantly altered due to CIS administration when compared to the control group. RSV at different doses reversed the changes made in only GSH, SOD and CAT across all groups. CIS-induced MDA increase was reduced significantly only in groups $\mathrm{C}$ and $\mathrm{D}$ but not in $\mathrm{E}$ (higher dose) when compared to group B ( $P>0.05$, Table 5). 


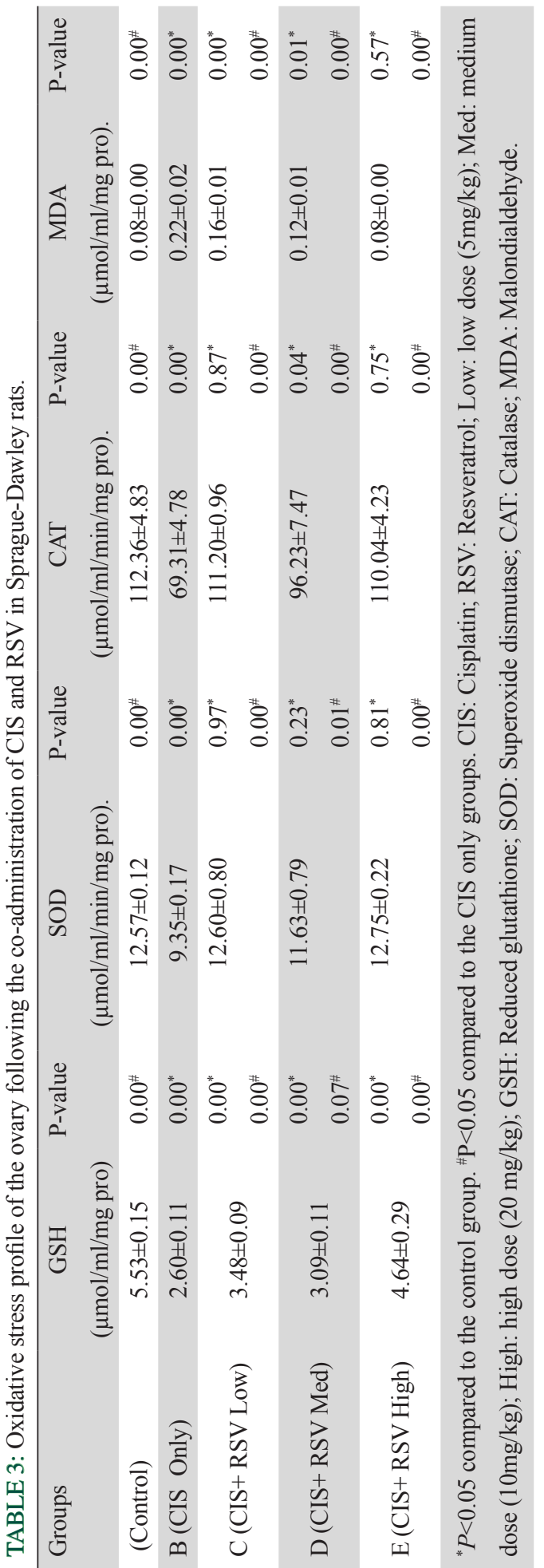

\section{Stomach oxidant status}

The CIS administration caused a significant change in GSH, SOD, CAT and MDA levels in CIS-treated groups which were reversed to normal by RSV administration across all groups when compared to both group B and the control group $(P<0.05)$. However, RSV at a lower dose (group C) did not reverse the effect of cisplatin on

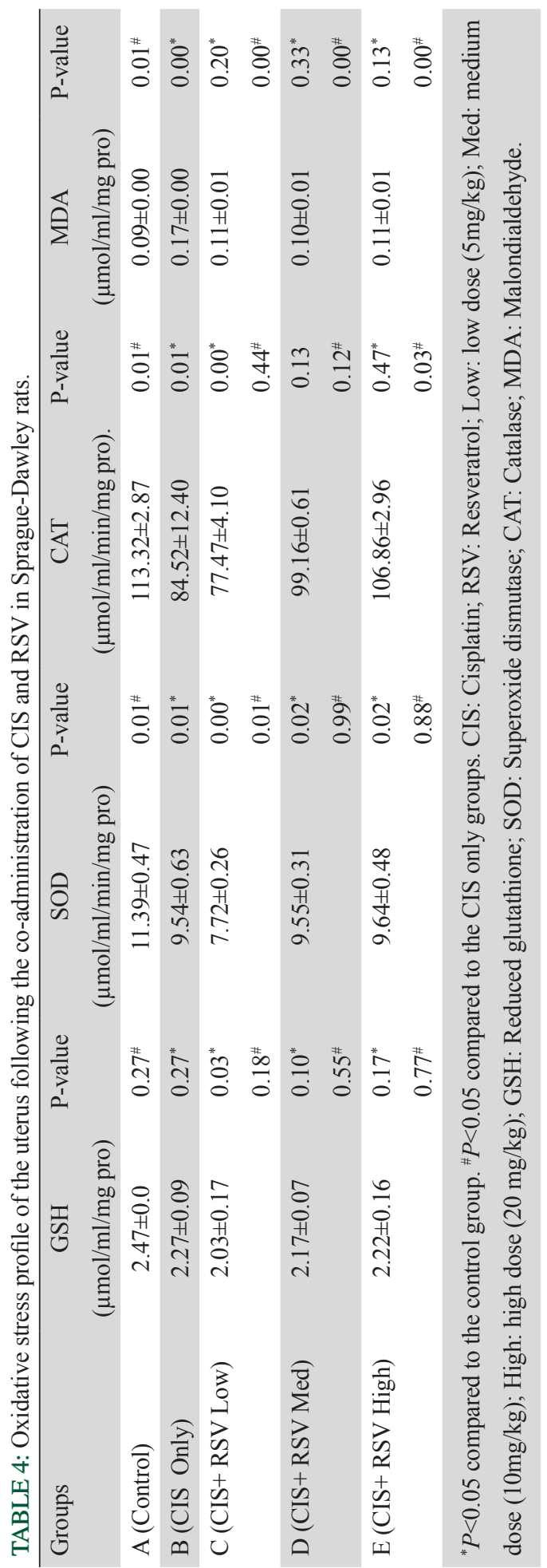

the MDA level as group $\mathrm{C}$ showed significantly higher MDA levels compared to the control group. Also, RSV did not reverse the GSH levels in the stomach across all the RSV-treated groups $(P<0.05$, Table 6).

\section{Pancreas oxidant status}

CIS administration caused a significant decrease in 


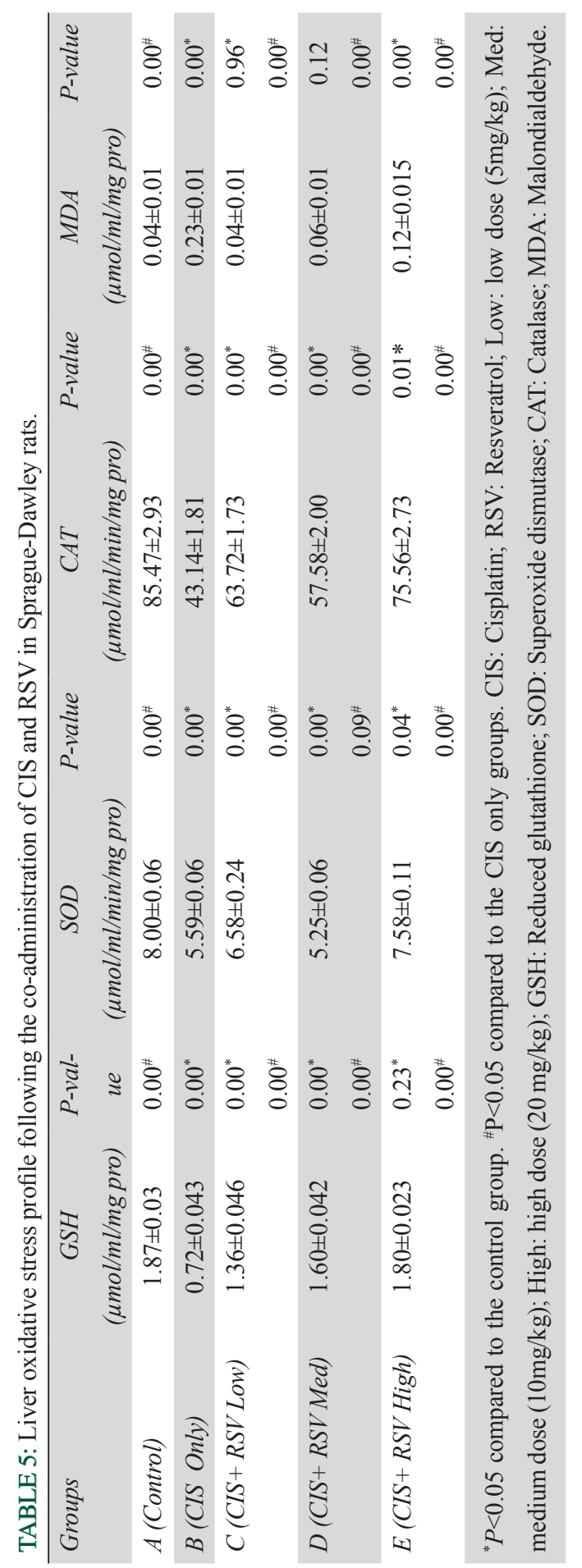

GSH, SOD and CAT across all groups when compared to the control group $(P<0.05)$. RSV co-administration in groups $\mathrm{C}, \mathrm{D}$ and $\mathrm{E}$ caused a sharp decrease and reversal of GSH, SOD and CAT levels when compared to the control and cisplatin groups $(P<0.05)$. However, there is no change in MDA levels due to CIS administration across all the treated groups $(P<0.05$, Table 7$)$.

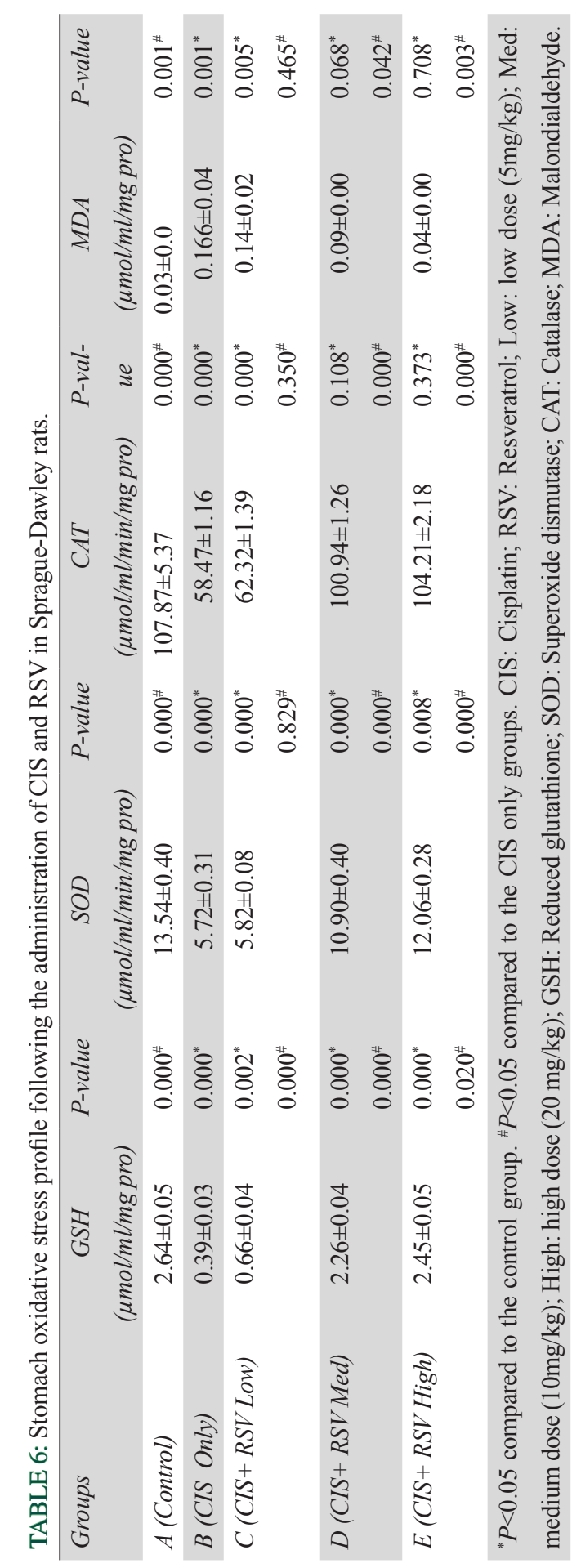

Table 8 shows that GSH, CAT, SOD and MDA were significantly altered across CIS-treated groups when compared to the control group $(P<0.05)$. The subsequent administration of RSV caused the reversal of these changes only in groups D (for MDA and SOD) and $\mathrm{E}$ (for GSH, CAT and MDA; $P<0.05$ ).

\section{Kidney oxidant status}

Table 9 shows the effect of CIS and resveratrol on 


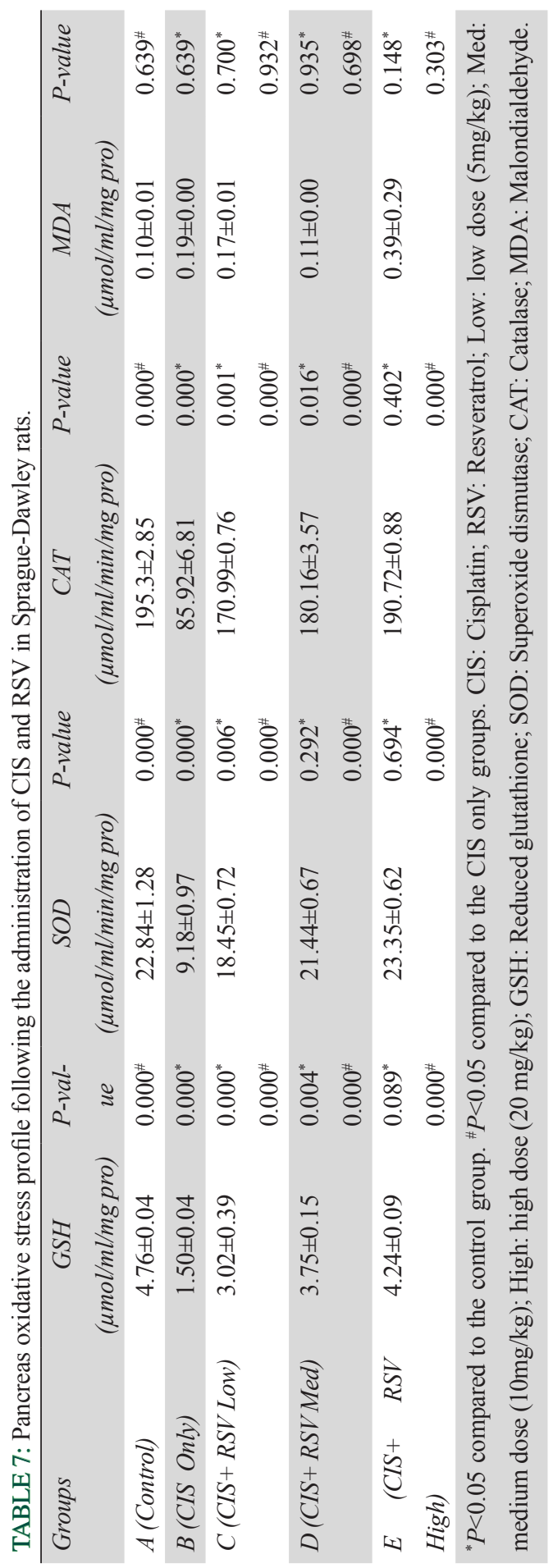

the GSH, SOD, CAT and MDA levels in rats. CIS administration caused a significant decrease in GSH, SOD and CAT across treated groups; but a significant increase in MDA compared to the control $(P<0.05)$. The RSV co-administration did not make any significant difference in any of the observed oxidative parameters across all treated groups except in group E, where GSH, SOD and CAT levels were not different compared to the control group $(P<0.05)$. MDA levels of group E

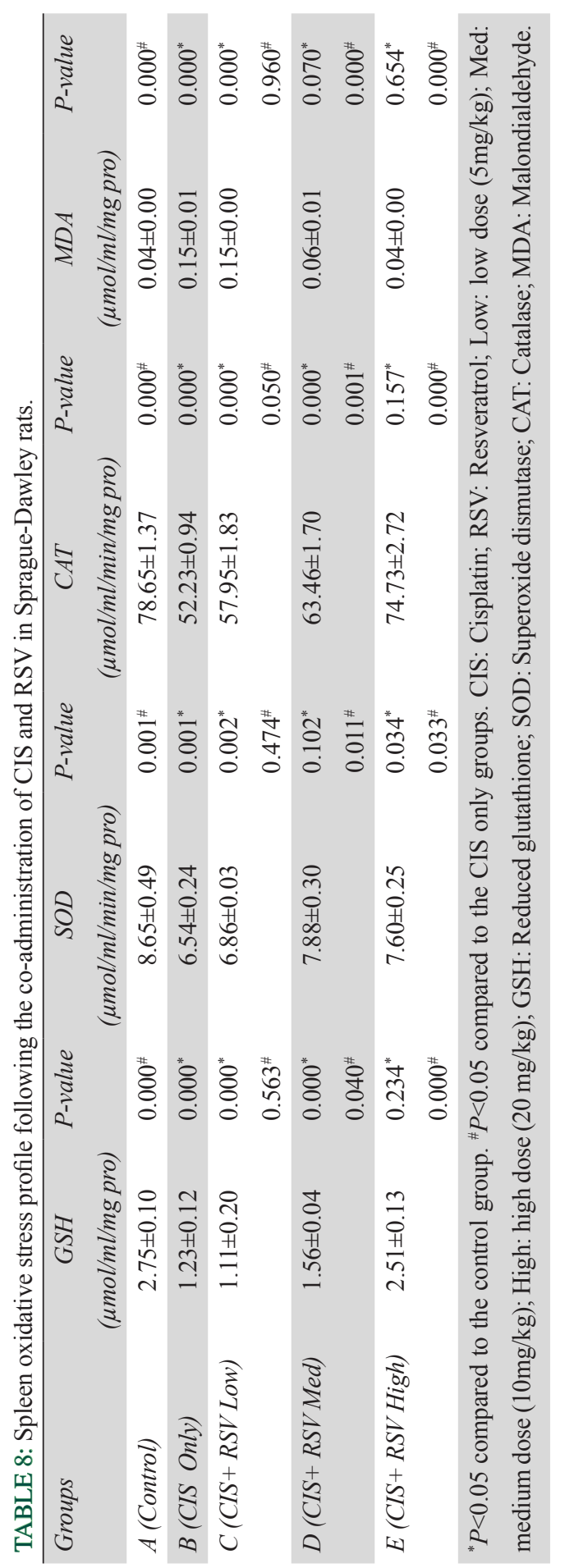

was significantly lower than the CIS group but was significantly higher compared to the control $(P<0.05)$.

\section{Discussion}

The RSV is a naturally occurring phytoalexin with numerous pharmacologic and therapeutic attributes including anti-inflammatory, anti-neoplastic and antidiabetic properties (Singh et al., 2019). RSV has also been shown to inhibit lipid peroxidation and reduced 


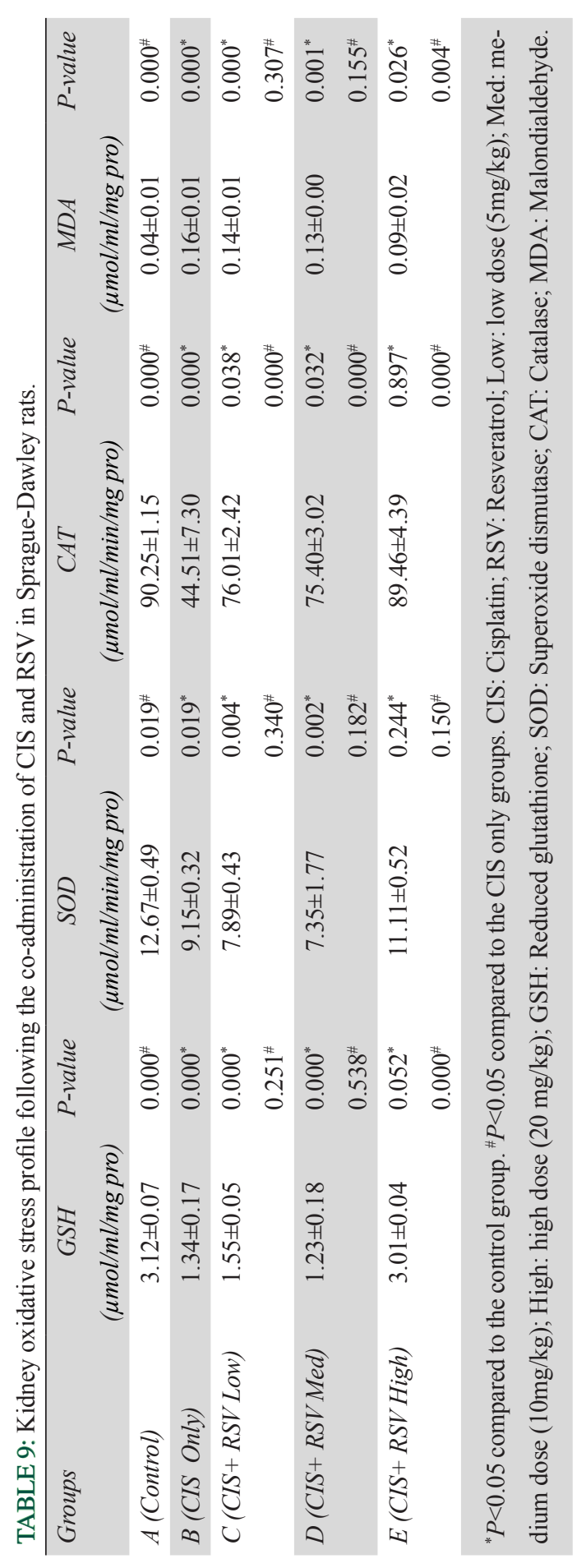

ROS production in different organs, thus protecting cells from oxidative damage (Akbel et al., 2018). Oxidative damage occurs when the production of free radicals or ROS surpasses or overwhelms the body's ability to counteract the actions of these reactive radicals. Free radicals produced in oxidative stress are known to interact with and damage important cellular components such as lipids, sugars, polynucleotides as well as proteins and may trigger cellular and tissue damage (Nandi et al., 2019). Decades of epidemiological evidence have shown the involvement of oxidative stress in the progression and pathogenesis of several chronic diseases (Negre-Salvayre et al., 2010; Granger et al., 2015). The widespread involvement of oxidative stress damage in different diseases has made oxidative stress markers an important indicator of general disease state, disease progression and toxicity. In the present study, the levels of some sensitive markers of oxidative stress 
in different body tissues were critically accessed and the changes that occurred following the co-administration of CIS and RSV were noted.

The administration of RSV twenty-four hours after CIS injection may have played a role in the effect seen on the mortality rate. The similarity of the death rate in groups B, D and E (Table 1) shows that RSV offers no protection against death as a result of cisplatin-induced toxicity. A higher CIS dose was used in the current study compared to other earlier studies (Okafor et al., 2014) which may be responsible for the number of deaths experienced. Howbeit, this present study lacks the evidence to claim that a different outcome could result if the dosing time differed.

The administration of $10 \mathrm{ml} / \mathrm{kg}$ CIS showed a significant effect on the body weight of experimental animals when the body weight before and after drug administration was compared $(P=0.047$, Table 2$)$. There was a reduction in body weights which were not salvaged by the co-administrative effect of RSV. No single dose of RSV attenuated the effect of cisplatin on the bodyweight of animals. This finding agrees with an earlier study by Okafor and colleagues (2014) which showed the weight reduction ability of CIS.

MDA is an endogenous end product of ROS-mediated lipid peroxidation and is considered a good marker of oxidative stress. CIS significantly increased MDA levels in different tissues assessed in this study. The mean values of MDA in ovary, uterus, liver, stomach, spleen and kidney were significantly increased in group B given only CIS injection when compared to the control. The increased MDA level observed in this study may be indicative of an increased polyunsaturated fatty acid oxidation, which is an important hallmark of oxidative stress (Marrocco et al., 2017). The elevated MDA levels observed in this study corroborated the findings of Ince et al. (2014), who reported a significant increase in MDA levels following intraperitoneal injection of $7 \mathrm{~kg} / \mathrm{mg}$ CIS. However, CIS did not cause the same effect on the pancreas as there is no difference with the MDA levels in group B compared to the control. The changes seen in the MDA levels were all reversed by RSV across the tissues in a dose-dependent manner with few exceptions (Tables 3-9). While only 10 and $20 \mathrm{mg} /$ $\mathrm{kg}$ RSV doses caused the tissues' toxicity recovery in the stomach and spleen (Tables 6 and 8), only $20 \mathrm{mg} / \mathrm{kg}$ RSV was able to cause a significant difference in MDA levels in the kidney when compared to group B (Table 9). Our finding is comparable to the studies of Gedik et al. (2008), which reported a significant decrease in MDA levels following the administration of RSV.

SOD and CAT compromise the body's antioxidant defense system as they form a formidable defense against ROS-mediated injury. SOD catalyzes the breakdown of superoxide anion radicals into $\mathrm{H}_{2} \mathrm{O}_{2}$ and molecular oxygen (Younus, 2018); while CAT catalyzes the breakdown of hydrogen $\mathrm{H}_{2} \mathrm{O}_{2}$ into $\mathrm{H}_{2} \mathrm{O}$ and molecular oxygen (Nandi et al., 2019). The RSV treatment attenuated the effect of CIS on CAT and SOD in a dose-dependent manner in the ovary, liver, stomach and pancreas of all the treated groups (Tables 5-7). The CAT levels were seen to decrease compared to the control after treatment with the $10 \mathrm{mg} / \mathrm{kg}$ RSV in the ovary while only the high dose $(20 \mathrm{mg} / \mathrm{kg})$ was able to attenuate the CIS effect in the uterus, spleen and kidney (Tables 4, 8 and 9). It is also worthy to note that in the kidney, the CAT levels of all the RSV-treated groups were seen to be significantly higher when compared to group B (CIS only group, Table 9). Meanwhile, only the $20 \mathrm{mg} / \mathrm{kg}$ and $10 \mathrm{mg} / \mathrm{kg}$ RSV treatment caused restoration of SOD levels to comparable normal values in the kidney and spleen respectively (Tables 8 and 9); while RSV showed no antioxidative potential against CIS effects in uterus across all the treated groups (Table 4).

The observation of the endogenous, non-enzymatic antioxidant - GSH showed that outside the uterus, all other evaluated tissues showed a significantly lowered GSH levels due to CIS treatment when compared to the control group (Tables 3-9). In addition to the role of GSH in the detoxification of ROS, GSH also regenerates important antioxidants like vitamin $\mathrm{C}$ and $\mathrm{E}$ and has been reported to be involved in the redox reaction associated with DNA repair. Studies on the pro-oxidant and toxic properties of CIS abound (Mir et al., 2015; Wang et al., 2017) and the result of this study supports these data. However, all the doses of RSV were effective in the treatment of CIS-induced GSH decrease across several tissues including the ovary, liver and pancreas (Tables 3, 5 and 7). While RSV treatment at all doses was not able to cause the reversal of GSH to normal levels in the uterus and stomach, only the high dose RSV $(20 \mathrm{mg} / \mathrm{kg})$ effectively reversed the GSH to normal levels in spleen and kidney (Tables 8 and 9).

Following the indicative findings, it can be posited 
that RSV is a potent antioxidant. The dose-dependent antioxidant effect of RSV could be mainly as a result of its ability to improve the antioxidant capacity of tissues, rather than a direct free-scavenging activity. Fukui and colleagues (2010) made similar observations in their study which reported that RSV up-regulates cell mitochondrial antioxidants through the activation of the P13K/Akt signaling pathway. Similarly, Liu and colleagues (2015) suggested that the mediation of several intracellular signaling pathways including NOS, HO-1, SIRT1, among others, plays an important role in the organ-protective effect of RSV. The variation in the activities of RSV seen across different tissues could be as a result of the drug metabolic rate of RSV in the tissues or due to the level of oxidative activity produced by CIS administration. More so, the interplay of proximity of the tissues to one another and the substance distribution channels through the blood could determine the level of effects seen in the RSV antioxidative pattern. It is worthy to note that RSV showed a more effective antioxidative potential in all the observed tissues at a higher dose of $20 \mathrm{mg} / \mathrm{kg}$ in most of the oxidative stress markers.

\section{Conclusion}

Overall, CIS induced oxidative stress and compromised the antioxidant capacity of body tissues, while RSV attenuated the induced toxic effect. In the search for effective drug combination therapies to cushion the effects of CIS chemotherapy, this study has provides compelling preliminary evidence that RSV supplementation in the right dosage is protective against CIS-induced oxidative stress damage in different body tissues and possesses the potential of effective combination therapy with CIS. However, more studies need to be carried out to ascertain the dose-related pharmacodynamics of RSV in CIS-induced oxidative stress.

\section{Acknowledgment}

I want to thank Mr. Jude Nnaka who helped with the manuscript editing and Mr. Johnson Nweke who performed the data analysis.

\section{Conflict of interest}

There is no conflict of interest to declare.

\section{Availability of data}

The dataset for this study has been deposited in
Figshare repository - (https://doi.org/10.6084/m9. figshare.12413438.v1)

\section{Funding source}

No funding was received for this study.

\section{References}

Akbel E, Arslan-Acaroz D, Demirel HH, Kucukkurt I, Ince $\mathrm{S}$. The subchronic exposure to malathion, an organophosphate pesticide, causes lipid peroxidation, oxidative stress, and tissue damage in rats: the protective role of resveratrol. Toxicol Res 2018; 7: 503-12. https://doi.org/10.1039/ C8TX00030A

Amin A, Hamza AA, Kambal A, Daoud S. Herbal extracts counteract cisplatin-induced cell death in rat testis. Asian J Androl 2008;10: 291-7. https://doi.org/10.1111/j.17457262.2008.00379.x

Athar M, Back JH, Kopelovich L, Bickers DR, Kim AL. Multiple molecular targets of resveratrol: anti-carcinogenic mechanisms. Arch Biochem Biophys 2009; 486: 95-102. https://doi.org/10.1016/j.abb.2009.01.018

Bhattacharjee S. Reactive oxygen species and oxidative burst: roles in stress, senescence and signal transducation in plants. Curr Sci 2005; 10: 1113-21.

Bolis G, Favalli G, Danese S, Zanaboni F, Mangili G, Scarabelli $\mathrm{C}$, et al. Weekly cisplatin given for 2 months versus cisplatin plus cyclophosphamide given for 5 months after cytoreductive surgery for advanced ovarian cancer. J Clin Oncol 1997; 15: 1938-44. https://doi.org/10.1200/ JCO.1997.15.5.1938

Coppin CM, Gospodarowicz MK, James K, Tannock IF, Zee $\mathrm{B}$, Carson J, et al. Improved local control of invasive bladder cancer by concurrent cisplatin and preoperative or definitive radiation. J Clin Oncol 1996; 14: 2901-7. https:// doi.org/10.1200/JCO.1996.14.11.2901

Coskun N, Hatipoglu MT, Özoğul C, Korkmaz C, Akyol SN, Micilı SC, et al. The protective effects of acetyl L-carnitine on testis gonadotoxicity induced by Cisplatin in rats. Balkan Med J 2013; 30: 235. https://doi.org/10.5152/balkanmedj.2013.7340

Frémont L. Biological effects of resveratrol. Life Sci 2000; 66: 663-73. https://doi.org/10.1016/S0024-3205(99)004105

Fukui M, Choi HJ, Zhu BT. Mechanism for the protective effect of resveratrol against oxidative stress-induced neuronal death. Free Radic Biol Med 2010; 49: 800-13. https://doi. org/10.1016/j.freeradbiomed.2010.06.002 
Gedik E, Girgin S, Ozturk H, Obay BD, Ozturk H, Buyukbayram $\mathrm{H}$. Resveratrol attenuates oxidative stress and histological alterations induced by liver ischemia/reperfusion in rats. World J Gastroenterol 2008; 14: 7101. https://doi. org/10.3748/wjg.14.7101

Granger DN, Kvietys PR. Reperfusion injury and reactive oxygen species: the evolution of a concept. Redox Biol 2015; 6: 524-51. https://doi.org/10.1016/j.redox.2015.08.020

Hamadi N, Mansour A, Hassan MH, Khalifi-Touhami F, Badagry O. Ameliorative effects of resveratrol on liver injury in streptozotocin-induced diabetic rats. J Biochem Mol Toxicol 2012; 26: 384-92. https://doi.org/10.1002/jbt.21432

Hanchate LP, Sharma SR, Madyalkar S. Cisplatininduced acute myocardial infarction and dyslipidemia. J Clin Diagn Res 2017; 11. https://doi.org/10.7860/JCDR/2017/25546.10025

Ince S, Acaroz DA, Neuwirth O, Demirel HH, Denk B, Kucukkurt I, et al. Protective effect of polydatin, a natural precursor of resveratrol, against Cisplatin-induced toxicity in rats. Food Chem Toxicol 2014; 72: 147-53. https://doi. org/10.1016/j.fct.2014.07.022

Liu FC, Tsai HI, Yu HP. Organ-protective effect of red wine extract, resveratrol, in oxidative stress-mediated reperfusion injury. Oxid Med Cell Longev 2015. https://oi. org $/ 10.1155 / 2015 / 568634$

Loehrer Sr PJ, Gonin R, Nichols CR, Weathers T, Einhorn LH. Vinblastine plus ifosphamide plus cisplatin as initial salvage therapy in recurrent germ cell tumor. J Clin Oncol 1998; 16: 2500-4. https://doi.org/10.1200/JCO.1998.16.7.2500

Marrocco I, Altieri F, Peluso I. Measurement and clinical significance of biomarkers of oxidative stress in humans. Oxid Med Cell Longev 2017. https://doi. org/10.1155/2017/6501046

Mir M, Arab RM, Shahraki MR, Mashhadi MA, Salar MS, Aval FS, et al. Toxic effects of cisplatin on hepatocytes and liver enzymes of rats. Anat Sci 2015.

Nandi A, Yan LJ, Jana CK, Das N. Role of catalase in oxidative stress- and age-associated degenerative diseases. Oxid Med Cell Longev 2019. https://doi.org/10.1155/2019/9613090

National Health Research Ethics Committee of Nigeria. Federal Ministry of health. 2014. Available at http://nhrec.net/ nhrec/wp-content/uploads/2018/10/Final-Sub-code-for-Research-involving-animal-use-v2.pdf. Accessed 20th October 2016.

National Research Council (US) Committee for the update of the Guild for the Care and Use of Laboratory Animals. Guild for the Care and Use of Laboratory Animals. 8th edition. Washington (DC): National Academies Press (US).
2011. Available at https:/grants.nih.gov/grants/olaw/guidefor-the-care-and-use-of-laboratory-animals.pdf. Accessed 16th October 2016.

Negre-Salvayre A, Auge N, Ayala V, Basaga H, Boada J, Brenke R, et al. Pathological aspects of lipid peroxidation. Free Radic Res 2010; 44: 1125-71. https://doi.org/10.3109/ 10715762.2010.498478

Nematbakhsh M, Ashrafi F, Pezeshki Z, Fatahi Z, Kianpoor F, Sanei MH, et al. A histopathological study of nephrotoxicity, hepatoxicity or testicular toxicity: Which one is the first observation as side effect of cisplatin-induced toxicity in animal model? J Nephropathol 2012; 1: 190. https://doi. org/10.5812/nephropathol.8122

Okafor IA, Ezejindu DN, Chukwujekwu IE, Dikeh CC. Evaluation of the side effects of cisplatin drug in a nephrotoxicity model of Wistar rats. J Biol Agricul Healthcare 2014; 4. Rose PG, Bundy BN, Watkins EB, Thigpen JT, Deppe G, Maiman MA, et al. Concurrent cisplatin-based radiotherapy and chemotherapy for locally advanced cervical cancer. N Engl J Med 1999; 340: 1144-53. https://doi.org/10.1056/NEJM199904153401502

Rukkumani R, Aruna K, Varma PS, Rajasekaran KN, Menon VP. Comparative effects of curcumin and an analog of curcumin on alcohol and PUFA induced oxidative stress. J Pharm Sci 2004; 7: 274-83.

Shrikanta A, Kumar A, Govindaswamy V. Resveratrol content and antioxidant properties of underutilized fruits. J Food Sci Technol 2015; 52: 383-90. https://doi.org/10.1007/s13197013-0993-Z

Singh AP, Singh R, Verma SS, Rai V, Kaschula CH, Maiti $\mathrm{P}$, et al. Health benefits of resveratrol: evidence from clinical studies. Med Res Rev 2019; 39: 1851-91. https://doi. org/10.1002/med.21565

Stakisaitis D, Dudeniene G, Jankunas RJ, Grazeliene G, Didziapetriene J, Pundziene B. Cisplatin increases urinary sodium excretion in rats: gender-related differences. Medicina 2010; 46: 45-50. https://doi.org/10.3390/medicina46010008

Sun YI, Oberley LW, Li Y. A simple method for clinical assay of superoxide dismutase. Clin Chem 1998; 34: 497-500. https://doi.org/10.1093/clinchem/34.3.497

Szkudelska K, Szkudelski T. Resveratrol, obesity and diabetes. Eur J Pharmacol 2010; 635: 1-8. https://doi.org/10.1016/j. ejphar.2010.02.054

Tadolini B, Juliano C, Piu L, Franconi F, Cabrini L. Resveratrol inhibition of lipid peroxidation. Free Radic Res 2000; 33: 105-14. https://doi.org/10.1080/10715760000300661 
Wang G, Su C, Yin T. Paclitaxel and platinum based chemotherapy results in transient dyslipidemia in cancer patients. Mol Clin Oncol 2017; 6: 261-5. https://doi.org/10.3892/ mco.2016.1107

Watanabe KI, Hess A, Bloch W, Michel O. Nitric oxide synthase inhibitor suppresses the ototoxic side effect of Cisplatin in guinea pigs. Anti-Cancer Drugs 2000; 11: 401-6. https://doi.org/10.1097/00001813-200006000-00011

Yao X, Panichpisal K, Kurtzman N, Nugent K. Cisplatin nephrotoxicity: a review. Am J Med Sci 2007; 334: 115-24. https://doi.org/10.1097/MAJ.0b013e31812dfe1e

Younus H. Therapeutic potential of superoxide dismutase. Int J Health Sci 2018; 12: 88. 